\title{
DE MONTES E MONTANHAS À PAISAGEM - REFLEXÕES SOBRE SUA ABORDAGEM ESTÉTICA
}

\section{FROM HILLS AND MOUNTAINS TO THE LANDSCAPE - REFLECTIONS ON ITS AESTHETIC APPROACH}

\author{
Camila Conti
}

\section{Resumo}

Montes e montanhas participam diretamente da vida nos lugares, assim como da história das concepções de paisagem. O objetivo deste artigo é levantar a discussão sobre as abordagens da sensibilidade estética na paisagem em relação às formas expressivas de relevo, e de sua pertinência aos problemas que se apresentam no horizonte atual das transformações espaciais. Parte-se da preocupação de não reduzir a questão do estético ao caráter das representações mentais da natureza, que ainda se mantém atreladas a essas formações. Conclui-se pela importância de uma consciência estética como expressão de uma cumplicidade humana com as formas da Terra.

Palavras-chave: Paisagem. Estética. Montes. Morros. Montanhas. Experiência.

\section{Abstract}

Hills and mountains engage in the life of places, as well as in the history of landscape's conceptions. The aim of this article is to discuss about the approaches to aesthetic sensitivity in the landscape in relation to the forms of expressive topography and its adequacy to crucial issues of our current spatial transformations. It begins with the concern about reducing the question of the aesthetic to the character of mental representations of nature, that still remain linked to these formations. It comes to the consideration of the importance of aesthetic awareness as an expression of a human complicity with the forms of the Earth.

Keywords: Landscape, aesthetics, hills, mountains, experience. 


\section{INTRODUÇÃo}

Vivendo no Brasil em cidades pequenas, grandes ou em megalópoles, em campos tomados ou não pelo agronegócio e em morros tomados ou não pela mineração, reconhecemos uma vida que se dá entre feições de relevo da Terra.

Muitas vezes expressivas e elevadas, como morros e serras, essas formações participam da vida dos lugares. Em algumas ocasiões essa vida se dá em um embate nem sempre evidente, como no crescimento de cidades que avançam espacialmente de modo homogêneo ignorando muitas vezes as singularidades topográficas. Outras vezes, quando bastante evidente e desequilibrado, esse embate de forças pode também tomar a face trágica da morte, como ocorrido no rompimento das barragens de rejeitos de mineração em Bento Rodrigues em 2015 e em Brumadinho em 2019, ambas em Minas Gerais, cuja lama matou pessoas, animais e rios, e destruiu localidades inteiras.

Montes e montanhas participam, por sua vez, da história das concepções estéticas da paisagem no ocidente. No entanto, como expressa Schama (1996, p. 18), essas paisagens não configuraram apenas uma topografia arranjada para deleitar os olhos, e as memórias que elas despertam não são todas "piqueniques pastorais". Os processos de colonização europeia são tão cercados de expressões míticas de montanhas reveladoras, que as primeiras expedições aos cumes de montanhas, seguidas pelo alpinismo dos séculos XVIII e XIX, poderiam ser consideradas um exercício de "colonialismo vertical", como chamou Schama (1996, p. 423).

Este artigo propõe tecer uma revisão bibliográfica sobre a abordagem das formas expressivas de relevo. Uma vez que tanto a paisagem como a sensibilidade estética a essas formações oferecem possibilidades diversas, a postura adotada foi a de buscar identificar e analisar distinções entre algumas abordagens, entendendo que elas não apenas abrem caminhos interpretativos, mas apontam para resultados diferentes diante da realidade e da forma como praticamos o espaço.

\section{As Representações Culturais do Natural}

A contemplação das feições elevadas de relevo possui seu lugar próprio e bastante conhecido nas concepções estéticas da paisagem no ocidente. Podemos, por exemplo, seguir a historiografia que nos conta sobre a aparição da montanha como objeto paisagístico na pintura e sua relação com o surgimento de categorias estéticas, como a do "sublime" (BESSE, 2014a; RITTER, 1997; ROGER, 2000; SCHAMA, 1996).

Nesse contexto específico de invenção europeia, Roger (2000, p.37) nos lembra, por exemplo, que até o século XVIII o que era chamado paisagem se limitava aos campos bucólicos enquadrados na pintura flamenga de meados do século XV. Em contraposição ao campo, como "país tranquilo", a região montanhosa seria o "país pavoroso" presente nos relatos de viajantes. Para que o cenário montanhoso fosse reconhecido como paisagem, seria necessário que escritores como Haller, Gessner, Rousseau e Saussure e seus gravadores, como Aberli, Linck, Wolf, revelassem a visão dos "sublimes horrores".

Schama (1996) nos mostra que essa invenção se deu de maneira bem mais complexa. Ao menos duas visões dominantes sobre montes e montanhas chegaram ao século XVIII, herdadas do desenvolvimento integrado, tanto das expressões artísticas como das teorias sobre as origens da Terra e das expedições empíricas ocorridas nos séculos anteriores. De um lado, estaria o caráter benigno das montanhas do humanismo platônico com historiadores naturalistas, como John Ray, que, no século XVII, buscavam nelas o propósito divino da criação como fundamento de sua utilidade humana; de outro lado, estaria a dramatização das irregularidades naturais introduzida no mesmo século pela cosmologia do Telluris Theoria Sacra de Burnet (SCHAMA, 1996, p. 451). Expressa nas pinturas de Salvator Rosa, a dramatização do relevo inspirou escritores do século XVIII, como Horace Walpole e Thomas Gray, na concepção dos sublimes horrores. Assim, passou-se a celebrar a beleza horrível, selvagem, rejeitada pela convenção estética de então, estabelecida, por exemplo, na pintura de Claude Lorrain (SCHAMA, 1996, p. 456-457). 
Veem-se refletidas na abordagem da invenção da montanha as bases do conceito da "dupla artialização" de Roger (2011), segundo o qual, tanto nossa percepção direta como a possibilidade de uma experiência estética do natural seriam intermediadas por uma elaboração da arte. In visu, a arte se tornaria uma modeladora dos olhares ao instituir no olhar coletivo, os modelos de visão, os esquemas de percepção e de deleite. In situ, a arte também seria modeladora, ao inscrever o código artístico sobre a materialidade, a "substância corporal" da Terra que acaba revestida daquilo que é "sobrenatural" (ROGER, 2011, p. 158). O natural existe, então, na forma do pays, como uma extensão da terra, um "grau zero" da paisagem que precede a artialização. Pressupõe-se, assim, que a paisagem não existe naturalmente, e sim é inventada por modelos de visão do natural.

Conforme mostra Besse (2014a, p. 20), seria essa a abordagem que nos permitiria falar em representações mentais, culturais ou sociais e que possibilitaria associar certos lugares ou formações naturais com imaginários de grupos, inclusive os concernentes a identidades nacionais apoiadas em estereótipos. Ao abordar a paisagem a partir desse entendimento, ou seja, como representação, percebemos as formas naturais por meio de concepções culturais, isto é, consideramos que elas reúnem valores e significados da sociedade. Diante dessa abordagem, Besse identifica desafios a serem vencidos, relacionados à necessidade de se criar as novas linguagens por meio das quais poderíamos ler e apreciar os objetos paisagísticos que, na nossa contemporaneidade, se tornam incompatíveis a categorias estéticas estabelecidas:

Se a linguagem do idílio e da Arcádia e a pintura de paisagem clássica (a de Claude, por exemplo) dialogam, elas fracassam, entretanto, quando se trata de expressar novas categorias estéticas e de incluir outros objetos paisagísticos.[...]

É difícil, na verdade, identificar as paisagens que estão aparecendo hoje. Talvez por ausência de distanciamento e pela falta de análise e, mais certamente, pela falta de palavras e de conceitos. Mas está claro que se faz necessária uma nova linguagem (BESSE, 2014a, p.22 e 25).

Ainda assim, o autor vê algo de promissor, como uma "certa forma de confiança" depositada nos artistas, uma esperança de que essas novas linguagens nos permitam ainda apreciar e viver nossas paisagens contemporâneas (BESSE 2014a, p.26).

Jullien (2018), em caminho inverso, reconhece uma certa desconfiança de que haveria justamente na abordagem centrada em esquemas de linguagem um risco prejudicial a esse potencial da paisagem. Para o autor, o fato de que o termo paisagem tenha surgido no ocidente a partir do recorte de uma vista representada na pintura, pode acabar embutindo à noção uma estrutura lógica específica; centrada no pressuposto da composição de elementos em uma vista diante da qual a mente humana poderia reunir em um todo significativo. Recuperando a análise de Françoise Chenet-Faugeras ${ }^{1}$, Jullien afirma que é sob a autoridade das ciências da linguagem que a própria estética contemporânea chegou à noção de paisagem partindo dessa visão-concepção, ou seja, como uma construção de representação mental. No entanto, o autor alerta que isso apenas pode ser feito "com base nas pressuposições linguísticas de um sujeito" (CHENET-FAUGERAS, 1995, p. 275 apud JULLIEN, 2018, p. 68); em outras palavras, limitando o significado ao sentido dado pela linguagem de alguém. Assim, se consideramos a paisagem como fruto de uma visão-concepção instauradora e juntarmos a isso o argumento de que o natural tenha menos valor intrínseco do que o que ganha culturalmente, estaríamos abertos ao risco de criarmos versões enviesadas de paisagem:

Aqui a paisagem é fruto de uma produção - uma "artialização", como dizem- que empreendo de acordo com os meus próprios esquemas. A consequência (prejudicial) é uma paisagem "enviesada" (Françoise Chenet-Faugeras).

\footnotetext{
1 CHENET-FAUGERAS, Françoise, "Le Paysage comme parti pris," In: ROGER, Alain. La Théo-
} rie du paysage en France, 1974-1994. Seyssel, France: Champ Vallon, 1995. 
Assim, batizamos a "paisagem" "com toda uma série de valores estéticos, comerciais e até ideológicos: esta 'assemblage' no lugar de outra."

Em suma, toda "terra" pode se tornar "paisagem"; tudo é elegível para o título. Eu preciso apenas ajustar meu olho adequadamente (JULLIEN, 2018, p. 71).

Dessa forma, ao contrário de Roger (2000, p. 38) que enxergava nas visões dos Alpes criadas pelos fotógrafos do século XIX a "invenção definitiva da alta montanha", para Jullien, a fotografia da montanha conteria um gesto monopolizador que restringe a possibilidade de experiência: "Existe uma visão monopolizadora; o olho está fixo e não pode mais vagar aqui e ali; as coisas estão reduzidas ao absoluto. O olhar está conquistado, puro espetáculo realmente" (JULLIEN, 2018, p. 74).

A consequência prejudicial de uma visão ideológica ou monopolizadora do natural pode ser trazida para o contexto brasileiro por meio de Diegues (2008). O autor mostra como na ocasião da criação de nossas primeiras áreas naturais protegidas, as políticas ambientais brasileiras operaram sob um contexto unívoco de percepções que resultaram negligentes em relação a outras percepções existentes do natural, limitadas quanto ao seu desempenho efetivo e injustas em relação às formas como se impuseram sobre populações que tradicionalmente mantinham as condições naturais dos locais. Prevaleceu a ideia de uma natureza "intocada" pela presença do homem, que configuraria um "mito moderno", concepção essencialmente urbana que acabou por conformar nossa tradição ocidental de pensamento ambiental, e foi importada, nesse caso específico da criação de nossas áreas protegidas, do modelo de Parques Nacionais norte-americanos do século XIX e sua proteção da "vida natural/selvagem" (wilderness).

Torna-se necessário compreender, como também nos mostra Diegues $(1998,2008)$, em seus estudos sobre populações tradicionais brasileiras, que de um lado nos colocamos diante de imagens, símbolos e representações que nossa sociedade oferece por meios abrangentes e que se transformam conforme as diferentes épocas. Por outro lado, lidamos com as experiências afetivas e imaginativas que as pessoas podem ter em seus lugares de vida em sua relação com formações naturais e que podem estar, sob diferentes graus, ligadas às maneiras como constroem e significam suas práticas cotidianas coletivas.

Diante do risco, lembrado por Jullien (2018), de nos mantermos presos ao viés de uma percepção cultural, partiremos na direção de outra abordagem estética, agora relacionada a essa experiência próxima, imbricada entre as feições de relevo. Nos dedicaremos, então, à dimensão de experiência da paisagem e às diferentes formulações sobre ela.

\section{A Experiência Sensível na Estética Moderna}

Ao abordar a paisagem enquanto experiência, somos levados a rever nossa relação com as formas existentes como dadas entre sujeito e objeto. Ultrapassamos a consideração do que existe enquanto um "fora", apreendido e abordado a partir de "representações mentais", e passamos ao entendimento da experiência como uma "exposição ao real". Como nos lembra Besse (2014a, p. 46), a paisagem sustenta uma dimensão da relação humana com o mundo e com a natureza que fala da "relação direta, imediata, física, com os elementos sensíveis do mundo terrestre".

No entanto, ao aproximar-se do tema da sensibilidade às feições do relevo na paisagem, poderíamos primeiro nos questionar sobre seu sentido, uma vez que, por exemplo, a teoria da paisagem encontrou na experiência da subida de Petrarca ao Monte Ventoux diferentes relações e possibilidades para o acontecimento de uma experiência sensível com os acidentes elevados da Terra.

Em carta datada de 1336, Petrarca narra a seu orientador espiritual o dia em que, acompanhado pelo irmão, decide subir a montanha gélida e pedregosa que havia contemplado em sua infância em Avignon e em Carpentras, na França, construindo em sua narrativa o paralelo com suas reflexões morais (BESSE, 2014b; RITTER, 1997).

Duas interpretações reconhecem nessa experiência do poeta e moralista italiano uma amostra de sensibilidade ao natural protagonizada pela sociedade moderna. 
Em uma primeira interpretação, fixada no século XIX por Jacob Burckhardt, haveria em Petrarca a sensibilidade moderna dos italianos da renascença, "atraídos pela natureza por um 'senso particular' de 'pesquisa e de saber científicos'" (BURCKHARDT, 1964 apud RITTER, 1997, p. 37). Considerou-se, então, que a renascença teria fundado o olhar da secularização, da objetividade dada na curiosidade e na autópsia da natureza e que Petrarca teria encontrado a fórmula da experiência paisagística moderna: "a da contemplação desinteressada, do alto, do mundo natural aberto ao olhar" (BESSE, 2014a, p. 2).

Já na interpretação de Ritter (1997), o relato de Petrarca corresponderia à refundação moderna da relação com o natural enquanto espírito teórico. A narrativa do poeta traduziria, em linguagem neo-platônica e cristã, o movimento espiritual da tradição grega da Theoria tou Kosmou. Esse fundamento intelectual revestiria a experiência sensível com um "significado universal" de experiência teórica da contemplação da natureza. Essa específica visão contemplativa é feita a partir de um impulso que parte do corporal para se efetuar como "incitação" ao espírito humano que busca, por meio desse sensível "transcender", chegar à intuição da "ordem do mundo".

É no sentido da universalidade do espírito teórico que Ritter apresenta a estética da paisagem como uma mediação necessária, colocada em resposta à natureza objetiva, copernicana da ciência natural, como retomada do mundo sensível. Tão universal quanto a teoria helenística, a solução moderna da natureza-paisagem comunicaria o "todo natural", pois, como lembra Ritter, "o objeto da teoria será sempre 'a natureza na sua totalidade'" (RITTER, 1997, p. 43). No entanto, esse espírito teórico estaria conferido agora não pelo conceito filosófico, mas por uma presença estética, evocada "por meio de imagens 'vivas' e saídas da interioridade" (RITTER, 1997, p. 65).

Seria engano considerar que essa concepção da sensibilidade pudesse carregar um sentido de oposição à natureza objetiva, uma vez que Ritter estabelece a complementaridade entre a "arte estética" e a "ciência lógica", remetendo seu fundamento à Aesthetica de Baumgarten de 1750 (RITTER, 1997, p. 69). Essa nova sensibilidade encontraria, portanto, fundamentos que se somam à objetivação. No poema Promenade de Schiller, escrito em homenagem a Rousseau, Ritter encontra os gestos do que seria essa sensibilidade moderna. O "promeneur solitário" canta evocando uma "montanha amada" como "encarnação da paisagem" e, assim, o estético põe em presença a natureza idealizada pelo sujeito moderno. Além disso, esse mesmo sujeito parte da cidade "em direção à natureza", afirmando sua liberdade tanto na objetivação, como no divórcio do ambiente natural: "A liberdade exige sua reificação em objeto, [...] perdendo a natureza que a envolvia e apagando as estrelas guias, a cidade tornou o homem livre enquanto homem" (RITTER, 1997, p. 79).

Por carregar o componente intelectual da transcendência da teoria e o distanciamento do natural, essa nova sensibilidade suplantaria o sentir "passivo" do homem considerado não moderno, configurando uma diferenciação. Deixando para trás o que seria um estado de indistinção, o homem moderno se torna o dominador de outros corpos naturais: "Escravo da natureza há tanto tempo que ele se limita a senti-la, o homem se torna seu legislador...Aquilo que é objeto para ele não tem poder sobre ele, pois esse objeto só pode ser tal submetendo seu poder a ele" (SCHILLER, 1943, p. 307 apud RITTER, 1997, p. 79). Estaria, portanto, fora de questão o retorno àquilo que Ritter chamaria de "unidade original", uma vez que a emancipação da natureza se torna a condição primeira da liberdade.

É importante frisar que em Ritter "natureza livre" e "homem livre" não caracterizam oposições a sistemas de dominação pelo trabaIho, limitando-se à distinção do sujeito citadino livre. Partindo do mesmo poema de Schiller, o autor lembra que a liberdade reside "na transformação da natureza que 'envolve' a existência rural em um objeto para dominação dos homens". Por esse motivo, entre as atividades classificadas como trabalho livre, atributo da cidade, encontram-se os trabalhos do "minerador que desaparece nas entranhas da montanha", assim como da exportação dos "dos bens de regiões distantes" e dos "frutos do labor indígena" (RITTER, 1997, p. 77).

Por fim, compreendemos que a estética da paisagem moderna, como proposta por Ritter, não trata apenas da formulação de uma 
sensibilidade ao natural, mas cumpre, como bem alerta o título de sua obra, uma função na sociedade moderna. Ao propor a mediação da estética à limitação imposta pela objetividade da ciência natural, Ritter acaba por formular uma sensibilidade ao natural feita sob o privilégio do que o autor considerou o fundamento da liberdade do homem moderno: "É então com a cidade, com a ciência e o trabalho que caracterizam a sociedade moderna, que a liberdade, como liberdade para o homem, adquire uma existência" (RITTER, 1997, p. 81).

Buscando assentar os pés em algum solo seguro para a abordagem da experiência estética dos acidentes de relevo elevados, terminaremos essa breve menção à paisagem e à função da estética na sociedade moderna, chamando a atenção para a necessidade atual de revermos alguns dos pressupostos dessas formulações.

\section{Desviando-Se do Naturalismo}

É necessário reconhecer que as incongruências da relação moderna de dominação da natureza, como externa à existência dos homens, e a concepção dessa natureza como um todo idealizado pelo espírito humano efetuam-se em nossa sociedade enquanto pressupostos do naturalismo.

Por naturalismo entende-se, a partir de Descola (1997, 2015), o princípio diretor de nossa cosmologia ocidental que não apenas se define pela qualificação de um domínio ontológico específico para o natural, como ente produtor de leis universais de ordem e necessidade; mas que caracteriza-se também pela qualificação de um mundo particular para os artíficios, signos, normas e produtos da criatividade humana. Ou seja, o naturalismo define-se pela "coexistência de uma única e conciliadora natureza e uma multiplicidade de culturas" (DESCOLA, 2015, p. 21). Nos encontramos, portanto, diante de um "multiculturalismo" que apaga a multiplicidade das coisas, pois se apoia na ideia de um "mononaturalismo" (LATOUR, 2004, p. 67).

Para Descola (1997), esse é apenas um dos possíveis "modos de identificação" que grupos humanos utilizam para definir as fronteiras do que consideram ou não como humano e para se socializar em meio à materialidade da Terra. Como modo de identificação dominante ocidental, desenvolvemos por meio do naturalismo as habilidades e conhecimentos em nossa comunidade de práticas (DESCOLA, 2015, p. 22). Ainda assim, conforme sugere Latour (2004), se torna urgente atualmente nos abstrairmos daquilo que o autor nomeia como Constituição moderna, a composição do mundo social que separa "a assembleia das coisas" da "assembleia dos humanos", uma vez que ela nos impede de convocar em nossas práticas sociais a pluralidade da existência terrestre.

Assim, Latour sugere que eliminemos a ideia de uma natureza única para nos colocarmos, enquanto humanos terrestres, diante da natureza imediata, isto é, para irmos em direção à "multiplicidade das naturezas" (LATOUR, 2004, p. 76):

Agora que a irrupção da natureza não vem mais paralisar a composição progressiva do mundo comum é necessário que nos tornemos capazes de convocar o coletivo encarregado doravante, como seu nome indica, de "coletar" a multiplicidade de associações de humanos e não-humanos [...] (LATOUR, 2004, p. 110).

Essa multiplicidade não partiria da divisão prévia entre um coletivo caracterizado como natureza e outro coletivo caracterizado como social. Se baseia, ao contrário, na convocação de um viver em comum a partir da ideia de um "social em associação". Assim, convoca-se um novo coletivo aberto, praticado e sempre novamente coletado na associação do humano e não-humano, considerado por Latour "em vias de expansão" (LATOUR, 2004, p. 73-74).

Desviando-se da compreensão de uma Natureza, criamos condições de abarcar o que Latour (2004, p. 110) considera a "composição progressiva do mundo comum" que, como veremos adiante, se torna útil ao entendimento da espacialidade aberta da paisagem, proporcionando outra concepção de sensibilidade.

\section{Em Busca de Outra Formulação Do Sensível}

Chegamos, já no século XXI, a uma nova interpretação da experiência de Petrarca no Monte Ventoux, elaborada por Besse (2014b), 
que se desvia do limite imposto pela solução moderna da paisagem e recupera, na subida e na reflexão do poeta italiano, a dimensão de uma vida que busca "tomar forma" no espaço.

A experiência de Petrarca é caracterizada como exemplo de uma "modernidade ambígua", uma vez que o poeta, ao chegar no topo da montanha, não encontra o eu apaziguado diante da "ordem natural do vasto mundo", mas se vê diante de um exame de consciência (BESSE, 2014b, p. 8). A subida de Petrarca expressaria "os tormentos de uma alma deslocada", dividida entre o impulso de evasão em meio do mundo, e o impulso contrário, de uma individualidade que se eleva a ponto de se destacar do mundo e negar toda existência aparente, buscando se refugiar no espírito.

Em paralelo a essa irresolução do poeta, encontra-se a tensão a que somos submetidos em nossa vida no espaço, como "pressentimento" de uma "vida tumultuosa" em meio ao mundo. Na carta de Petrarca a Andrea Dandolo, Besse encontra a passagem que mostra a ambivalência do sentimento do espaço nas expedições do poeta: "essa curiosidade de percorrer o mundo, tem não sei o que de doce e de penoso ao mesmo tempo" (PETRARCA apud BESSE, 2014b, p. 15). A experiência espacial é dolorosa, porque desafia o sujeito apresentando-se como alteridade. A paisagem, experimentada nesse limite, se torna, então, "uma deficiência do ser": "Se o espaço se opõe à unidade interior, é porque no espaço o ser não pode ser sem se diferenciar constantemente de si mesmo. $O$ espaço é o nome da diferença e da alteridade" (BESSE, 2014b, p. 14; grifo do autor).

Recuperando a fenomenologia de Erwin Straus, Besse lembra que a paisagem é "espaço do sentir", mas sem totalização e sem elevação espiritual, porque ela é "foco original de todo encontro com o mundo", ela fala do sentir como encontro do corpo na paisagem, como "experiência da proximidade das coisas" (BESSE, 2014b, p. 80).

Já no pensamento "desconcertante" e provisório de Charles Péguy, Besse encontra seu entendimento da "abertura" na experiência da paisagem, como uma inserção no presente de maneira específica. A experiência da paisagem fala da "força do presente" como local de uma atualidade aberta a possibilidades. Não remete, portanto, a um presente preenchido de uma memória que congela, se entendida como acumulação, como depósito de signos, como patrimônio ou nostalgia. Ao contrário, a paisagem se torna atitude de abertura diante do devir, da "passagem incompleta da vida": "Paisagem-evento, ela se abre a partir do ponto sensível do presente, na confluência exata de uma duração pessoal de tempo e do aparecer das coisas nesse instante" (BESSE, 2014b, p. 100).

Assim, no lugar do sensível que transcende para o recolhimento no espírito humano e que intui a "ordem do cosmos", o sensível é recuperado por meio de Péguy no "ponto sensível do presente", entendido como um ponto que "incita ao sentido". O ponto sensível é, como chama Besse, o "lugar da sensibilidade atingida" que se efetua em uma zona de contato: "Esta recuperação da significação e da sensibilidade é talvez o segredo do pensamento de Péguy. Há zonas sensíveis que é preciso saber achar, chegar nelas, se aproximar, saber tocar, ou antes, saber ser tocado, influenciado, animado por elas" (BESSE, 2014b, p. 100).

Besse encontra em Péguy a contrapartida do dispositivo moderno da percepção paisagística diante da qual Petrarca, além de não se tornar sujeito moderno, apontaria para a necessidade de uma atitude diante da tensão a que somos expostos no entre da paisagem, a que Besse sugere: "Ah! Que venha este cansaço da busca sempre frustrada, do cume mais alto e do ponto de vista! Desistamos do Lugar e caminhemos" (BESSE, 2014b, p. 105).

Tornar-se sensível na paisagem passa a significar tornar-se sensível ao "presente vivo", como experiência do real que vem diante de nós. A paisagem se torna um posicionamento diante do presente que não se recolhe na segurança de concepções pré-determinadas, ela expressa antes "seres singulares resistentes pela sua própria natureza à integração numa série, seja ela lógica, física ou moral" (BESSE, 2014b, p. 108).

\section{As Feições de Relevo no Espaço Concreto}

Apoiados em Besse (2014b), entendemos que a paisagem não constitui um espaço objetivo, nem o espaço da percepção ou da idealização, mas uma forma de experiência específica com o espa- 
ço exterior. A paisagem fala de "um certo modo de estar no mundo, uma ambiência, certa maneira, muito singular, de participar do movimento do mundo em determinado lugar"(BESSE, 2014a, p. 47).

No entanto, lembramos também que essa experiência da paisagem se coloca diante da vida praticada pelo humano que também intervém modificando a superfície da Terra, ou seja, ela acontece como como relação do homem com a materialidade terrestre.

Retomemos brevemente Latour (2004) como um apoio para entendermos que aquilo que consideraremos como a realidade do espaço concreto pressupõe um entendimento específico de uma relação entre o humano e as feições do relevo da Terra.

Latour sugere que, se pretendemos recolocar em marcha a experimentação do mundo comum, para poder dar a esse mundo um sentido político, entendido não como "conquista do poder", mas como a "composição progressiva de um mundo comum a compartilhar" (LATOUR, 2004, p. 88), precisaremos evitar a divisão prée uma da cultura. Recuperando a crítica de Whitehead ${ }^{2}$ sobre a originalidade dada ao espírito humano na distinção do real entre "qualidades primeiras" de natureza e "segundas" de cultura, Latour sugere que se mantenha a divisão apenas em uma dupla, a do humano e não-humano. Essa nova divisão não mais remeteria a uma partição prévia de todo o plural sob privilégio do humano, mas a uma incerteza: "uma dúvida profunda sobre a natureza da ação, a uma gama inteira de posições quanto às provas que permitem definir um ator" (LATOUR, 2004, p. 138). Pressupõe-se, assim, entre humanos e as feições de relevo, a relação que Latour chama de "recalcitrância" (LATOUR, 2004, p. 150), pois no campo de ação comum, atores se afetam mutuamente e aparecem como "importunos" uns aos outros.

É essa questão que podemos ver introduzida na abordagem fenomenológica da geografia de Dardel (1990), em seu entendimento do espaço geográfico, que consideraremos aqui como espaço concreto. Ao fazer o percurso da geografia como ciência, Dardel iden-

2 WHITEHEAD, Alfred North. Le Concept de nature. Paris: Vrin, 1998 [1920]

tifica a necessidade de recuperar seus vínculos com a "realidade geográfica primordial" do homem: "uma relação concreta se trava entre o homem e a Terra, uma geograficidade do homem como modo de sua existência e de seu destino" (DARDEL, 1990, p. 2).

Essa realidade concreta se expressa como uma espessura da vida na Terra, ela vem ressoar em nós na forma de movimento e de combate, expressões do dinamismo que acontece no espaço concreto. Essa experiência elementar é descrita por Dardel como "realidade -evento", que pode ser intuída apenas se recuperarmos a temporalidade de sua realização em posições múltiplas:

A alta montanha "se ergue" acima do vale, se "destaca" do maciço vizinho, valorizada pelas vertentes que a "faceiam". A localização desta montanha é a resultante destas relações recíprocas entre lugares-eventos. Como evitar abrir assim a espacialidade do espaço geográfico sobre sua perspectiva temporal? Não é a geografia, afinal de contas, uma certa maneira de sermos invadidos pela terra, o mar, a distância, de sermos dominados pela montanha, conduzidos pela direção, atualizados pela paisagem como presença na Terra?

Temporalização do nosso ambiente terrestre, espacialização da nossa finitude [...] (DARDEL, 1990, p. 54).

Entre o humano e a Terra se estabelece, para Dardel, "uma espécie de cumplicidade no ser" (DARDEL, 1990, p. 8). Essa cumplicidade se dá em realização e em irrealização, uma vez que o encontro com a Terra pode evocar tanto um "sim", que se abre ao humano e "o chama pela sedução dos cumes, ou pela atração subterrânea", como um "não", que, diante da solidez de uma corpo rochoso, se expressa "como um impenetrável mistério da natureza terrestre" (DARDEL, 1990, p. 21-22).

Assim, se essa realidade geográfica fala "para o homem", isso não se limita a um sentido de "no interesse" ou "para o uso" do homem, mas simplesmente exprime o ponto de vista humano. Não se deve, portanto, incorrer no erro de supor que a espacialização ocorra apenas de forma ativa pelo homem, uma vez que o homem pode ser "agido" pelo meio em que vive. O espaço geográfico se 
torna concreto e nos "inclina" para a Terra, pois deixa de ser realidade considerada como "exterior ao homem", que para Dardel significa "estranha ao seu destino", e passa a ser realidade como "interior" ou "íntimo", que para Dardel representa o "acessível" para a vida. O espaço concreto nos liberta do espaço geométrico infinito, esvaziado de todo conteúdo e inumano: "Ele nos instala em um espaço na nossa dimensão, em um espaço que se dá e que responde, espaço generoso e vivo aberto diante de nós" (DARDEL, 1990, p. 35).

Por ser participação, Dardel descreve o espaço geográfico a partir de seus valores afetivos. Entende-se aqui que não se trata simplesmente de uma abordagem "subjetiva" do espaço, mas justamente da consideração da incerteza da ação que abarca o encontro humano com a Terra de forma concreta:

"[...] não é, pois, de modo algum uma "coisa" indiferente, fechada sobre si mesma, da qual se dispõe ou que se pode dispensar. É sempre uma matéria que acolhe ou ameaça a liberdade humana. Uma região montanhosa não é, antes de mais nada, uma região que impõe obstáculo à circulação dos homens? A planície só é "vasta", a montanha só é "alta", na escala do homem, na medida de seus desígnos" (DARDEL, 1990, p. 10).

\section{A Estética Da Paisagem e O Viver Em Meio Às Formas Da TERra}

Por meio de Dardel (1990), devolvemos o papel ativo das formas do relevo à qualidade concreta do espaço. Seguimos o mesmo autor aderindo agora à sua definição da paisagem, que acrescenta ao que pudemos compreender do sensível de Besse (2014b), a dimensão especificamente terrestre de nossa existência, nos colocando a pensar as maneiras como praticamos nossa espacialização.

A paisagem é, no pensamento de Dardel, toda a espacialização geográfica, "porque é concreta e porque atualiza o próprio homem em sua existência" (DARDEL, 1990, p. 45). Diante das realidades geográficas e reunindo a experiência de toda concretude espacial,
Dardel afirma que ela se "unifica", entregando na experiência uma impressão em torno da presença humana na Terra:

Coisa bem diferente de uma justaposição de detalhes pitorescos, a paisagem é um conjunto: uma convergência, um momento vivido. Um laço interno, uma "impressão" une todos os elementos. [...] A paisagem se unifica em torno de uma tonalidade afetiva dominante, perfeitamente legítima embora refratária a toda redução puramente científica. Ela põe em questão a totalidade do ser humano, seus vínculos existenciais com a Terra, ou, se quisermos sua geograficidade original: a terra como lugar, base e meio de sua realização (DARDEL, 1990, p. 41-42).

Para Besse (1990), essa compreensão geográfica de Dardel carregaria um "fundamento ontológico" do homem enquanto terrestre. Essa geografia não falaria na forma do registro das ciências naturais, mas colocaria a questão de que o mundo geográfico, para se tornar acessível, recusa qualquer suposta neutralização sob um discurso universalizante: "A 'verdade' de que se trata em geografia, segundo Dardel, consiste menos na adequação, completamente exterior, de um discurso a um campo da realidade, do que na dependência de uma espécie de intensidade que atua na expressão" (BESSE, 1990, p. 165).Uma simpatia originária nos permite compreender as realidades concretas e, na paisagem, experimentamos as variações do existir humano sobre a Terra.

Chega-se, assim, ao caráter estético dessa experiência. Para Besse, a geografia de Dardel se apresentaria na maneira de uma "consciência estética", retomando o que seria o sentido mais geral da estética: "a experiência estética é primordialmente, uma sensibilidade às formas do mundo e o sentimento de afinidade profunda que liga os homens a essas formas" (BESSE, 1990, p. 172).

Nos afastamos da posição de Besse apenas no ponto em que o autor identifica aí uma aproximação com a sensibilidade moderna, incluindo a formulada por Ritter:

“[...] já que Dardel parece nos conduzir a uma orientação da geografia como "saber sensível", ele sanciona implici- 
tamente os resultados da história da ciência moderna. [...] Joachim Ritter mostrou bem como é a consciência estética que [...] permite à existência reencontrar uma dimensão cósmica, isto é manter com a Terra essa relação sensível e prática que dá à existência seu sentido concreto" (BESSE, 1990, p. 173-174).

Isso porque é possível verificar em Dardel um posicionamento específico que, justamente ao expor a maneira moderna de externalizar sua existência sobre a Terra, nos oferece caminho para a compreensão dos desafios colocados no horizonte das transformações espaciais que praticamos.

Quando formula sua história da geografia, Dardel afirma que a estética serviu no final do século XVIII à causa da compreensão geográfica da Terra. A exaltação sincera de Jean-Jacques Rousseau é vista pelo autor como uma incitação, um "refrescar" da sensibilidade que convidaria "a revigorar sua energia, a compreender melhor sua humana condição terrestre" (DARDEL, 1990, p. 115).

No entanto, o autor lembra que essa experiência vem a reboque da geografia cunhada de "a pleno vento":"capítulo da geografia heroica, heroísmo aqui como risco assumido, como a coragem da empreitada e da execução, a resolução de individualidades fortes" (DARDEL, 1990, p. 109).

Atrelada a essa geografia, Dardel descreve a cegueira geográfica praticada pelo humanismo moderno. De um lado, ela é expressa na visão do navegador humanista que realiza seu destino face a uma natureza. Ao procurar o "Paraíso terrestre", Cristovão Colombo se deixa ofuscar "pela luz de seu próprio mito" e, contra toda evidência, se entrega às tão conhecidas imprecisões geográficas da localização do que seria um novo continente (DARDEL, 1990, p. 111). De outro lado, estaria a geografia sentimental da expressão literária do romantismo que buscou na natureza, reconhecida no que seria o exótico, o consolo de suas inquietações pessoais. A geografia sentimental se encontrou envolta nas ilusões do século XVIII que, como lembra Dardel (1990, p. 114-115), "recebeu com complacência a lenda do 'bom selvagem' e do 'ingênuo hurão'". Em ambos os casos, é o homem e não a realidade geográfica que foi buscada: "o homem como centro de interesse e ocasião para a renovação das ideias" (DARDEL, 1990, p. 114).

Sob os códigos da modernidade, uma superioridade humana se efetua no espaço como uma afirmação de um sujeito que busca promover uma ordem visual do mundo. $O$ sujeito soberano é identificado por Dardel a partir do pensamento de Heidegger, tanto no homem dos séculos das Luzes, como no homem que se vê como nação, ambos permeados por uma vontade de poder que imporia sobre a Terra uma "disciplina da espécie":

No momento em que se propaga por todos os cantos esta espécie de homens que reduzem o espaço a objeto, a Terra, a matéria prima e a fonte de energia industrial, que dispõe de tudo e mesmo da vida humana de modo soberano, é necessário admitir que essa energia secreta que forma o homem de hoje com base em sua própria liberdade, não difere essencialmente de uma vontade de poder, tensionada por toda força de seu poder-ser e bastante permeável à paixão (DARDEL, 1990, p. 126-127).

A paisagem expressa a inserção do humano no mundo, como terrestre e como manifestação de seu "ser com os outros". No entanto, Dardel nos mostra que essa inserção se dá como lugar de um "combate pela vida" exposto à nossa condição atual. Muito objetivamente, o homem ocidental se impõe sobre outras vidas humanas e se impõe também nivelando as diferenças geográficas sob o império do que o autor alude como uma "civilização material uniforme" (DARDEL, 1990, p. 127).

Diante dessa condição, a paisagem se unifica em torno de uma verdade que não nos conta apenas sobre as mudanças do aspecto ou do desenho natural dos lugares. É na descrição do nordeste açucareiro do Brasil do início do século XX, feita por Josué de Castro, que Dardel, em vários momentos de seu texto, encontra o exemplo de uma verdade existencial na paisagem que não nega também os aspectos soturnos de nossa modernidade: "A morte domina todo o nordeste. Ela está sempre presente. Ela paira sobre toda a paisagem. Ela faz parte da vida" (DE CASTRO, P. 149 apud DARDEL, 1990, p. 44). Ao que Dardel confirma: “Uma verdade da paisagem 
se libera, não como teoria geográfica ou mesmo como valor estético, mas como expressão fiel da existência" (DARDEL, 1990, p. 44).

Diante da submissão material que se impõe à Terra e às pessoas, se multiplicariam também os meios que a modernidade busca para a retomada de um contato com o natural. Entretanto, esse contato é efetuado muitas vezes apenas como evasão que acaba por se configurar como fuga da responsabilidade atribuída à nossa condição terrestre:

Evasão, isto é com frequência a geografia no sentido de fuga de si mesmo, [...]. A superioridade que o homem moderno se atribui sobre o mundo circundante parece um obstáculo intransponível para uma harmonia sincera com a floresta, o mar e montanha. [...] Isso quando a viagem não é simplesmente um meio para homem desertar inautêntico, no 'divertimento', a gravidade da sua própria existência e as exigências da sua liberdade (DARDEL, 1990, p. 131).

A experiência estética da paisagem consagra, portanto, uma liberdade não descolada de nossa condição de presença na Terra. É nesse sentido que Dardel nos mostra que a Terra pode se tornar "desnaturada" para o homem, justamente quando esse se encontra privado da capacidade de reconhecer o "ritmo natural da vida no meio das coisas":

É um dos dramas do mundo contemporâneo o fato da Terra ter sido propriamente "desnaturada", do homem não poder mais "vê-la" a não ser através de medidas e cálculos, em vez de deixar que se decifre a ele sua escrita discreta e viva. Nossa civilização e uma ciência frequentemente entregue à vulgaridade multiplicaram o número de seres privados de toda seiva provincial, da sabedoria prudente e forte possibilitada pelo contato diário com a planície, a colina ou as ondas, do ritmo natural da vida no meio das coisas (DARDEL, 1990, p. 131-132) ${ }^{3}$.

30 acesso e a tradução livre das obras de Besse (1990), Dardel (1990) e Ritter (1997), apresentadas neste artigo, devem-se ao caderno Paisagem Textos 1, organizado em 2013 pelo Professor Dr. Vladimir Bartalini como subsídio ao curso de pós-graduação da Faculdade de Arquitetura e Urbanismo da Universidade de São Paulo.
Participamos, por mais modernos que sejamos, dos ritmos do mundo circundante, cuja qualidade concreta podemos apreender na experiência da paisagem. É nesse sentido que se considera a pertinência de uma consciência estética como uma cumplicidade comum que se estende às feições do relevo. Assim, parte-se não da idealização do natural, mas da sensibilidade como aquilo que poderia se dar, finalmente, como a "expressão de um 'acordo' do ser humano com as formas da Terra" (BESSE, 1990, p. 175).

\section{Considerações Finais}

Buscou-se, por meio da revisão bibliográfica apresentada, mostrar como a questão da sensibilidade estética às formas da superfície da Terra é atual e relevante. No entanto, é necessário percorrer o sentido exato que se atribui a essa sensibilidade, tanto sobre sua abordagem, para que não fique reduzida às representações mentais de natureza; como quanto à relação que estabelecemos com o natural, para que se reconheça seu papel em meio à vida comum no espaço concreto da paisagem.

Se pretendemos endereçar os problemas que se encontram no horizonte das transformações espaciais que operamos sobre as formas de relevo, precisamos considerar o papel do estético. Ele nos oferece um acordo do comum na paisagem, porque nos devolve os contornos da topografia em variação, negando o espaço homogêneo, isotrópico, que se estende a partir de um único ponto de vista, ou seja, como possibilidade de espacialização que supera o jugo da submissão material.

Mas além disso, reconhece-se também outra possibilidade de entendimento que pode ainda ser explorada, a de que, pela via do estético, nos permitamos também praticar uma cumplicidade como maneira de nos mantermos conectados à gravidade de nossa existência terrestre, uma vez que, ao menos enquanto vivemos a experiência sensível da paisagem, não somos indiferentes àquilo que apreendemos: "Em outras palavras, o que eu apreendo se transforma em parceria, e o cenário de tensão que singulariza o que eu apreendo me acolhe e me estimula a participar" (JULLIEN, 2018, p. 107) 


\section{ReferênCias Bibliográficas}

BESSE, Jean-Marc. Géographie et existence. In: DARDEL, Eric. L'homme et la terre. Nature de la réalité géographique. Paris: Editions du CTHS, 1990.

BESSE, Jean-Marc. As cinco portas da paisagem - ensaio de uma cartografia das problemáticas paisagísticas contemporâneas. In: BESSE, Jean-Marc. O gosto do mundo. Exercícios de paisagem. Rio de Janeiro: EdUERJ, 2014. a. p. 11-66.

BESSE, Jean-Marc. Ver a Terra: seis ensaios sobre a paisagem e a geografia. São Paulo: Perspectiva, 2014. b.

DARDEL, Eric. L'homme et la terre. Nature de la réalité géographique. Paris: Editions du CTHS, 1990

DESCOLA, Philippe. Ecologia e Cosmologia. In: CASTRO, E.; PINTON, F. (org.). Faces do trópico úmido: Conceitos e questões sobre Desenvolvimento e Meio Ambiente Belém: Editora Cejup, 1997. p. 243-261.

DESCOLA, Philippe. Além de Natureza e Cultura. Tessituras: Revista de Antropologia e Arqueologia, Tradução de Bruno Ribeiro. Pelotas, v. 3, p. 7-33, 2015. DOI: 10.15210/ tes.v3i1.5620.

DIEGUES, Antonio Carlos. Ilhas e Marés. Simbolimo e imaginário. São Paulo: São Paulo, 1998.

DIEGUES, Antonio Carlos. O Mito Moderno da Natureza Intocada. São Paulo: NUPAUB USP/ Hucitec, 2008.

JULLIEN, François. Living Off Landscape: or the Unthought-of in Reason. London/ New York: Rowman \& Littlefield Publishers, 2018

LATOUR, Bruno. Políticas da natureza: como fazer ciência na democracia. EDUSC ed. Bauru: EDUSC, 2004

RITTER, Joachim. Joachim Ritter, Paysage. Fonction de l'esthétique dans la societé moderne. Trad. Gérard Raulet. Besançon: Les Éditions de I'Imprimeur, 1997.

ROGER, Alain. La Naissance du Paysage en Occident. In: SALGUEIRO, Heliana A. (E.) Paisagem e Arte. CBHA/CNPq/Fapesp ed. São Paulo: São Paulo, 2000. p. 33-39.

ROGER, Alain. Natureza e Cultura. A dupla artialização. In: SERRÃO, Adriana Veríssimo (org.). Em Filosofia da Paisagem. Uma Antologia. Lisboa: Centro de Filosofia da Universidade de Lisboa, 2011. p. 153-166.

SCHAMA, Simon. Landscape and Memory. New York: Vintage Books, 1996.

\section{Camila Conti}

Universidade de São Paulo. Faculdade de Arquitetura e Urbanismo

Rua do Lago, 876 - Butantã, São Paulo - SP - 05508-080

https://orcid.org/0000-0002-8263-698X

camila.conti@usp.br
Nota do Editor:

Submetido em: 22/01/2021

Aprovação: 14/04/2021

Revisão: RMO 